\title{
Application of Intra-Particle Combustion Model for Iron Ore Sintering Bed
}

\author{
Pingli Hou ${ }^{1}$, Sangmin Choi $^{{ }^{*}}$, Won Yang ${ }^{2}$, Eungsoo Choi ${ }^{3}$, Heejin Kang ${ }^{1}$ \\ ${ }^{1}$ Department of Mechanical Engineering, Korea Advanced Institute of Science and Technology, Daejeon, Korea (South); ${ }^{2}$ Korea \\ Institute of Industrial Technology, Chungnam, Korea (South); ${ }^{3}$ Technology Research Lab, Ironmaking Research Group, OSCO, \\ Gyeongbuk, Korea (South). \\ Email: smchoi@kaist.ac.kr
}

Received February $16^{\text {th }}, 2011$; revised March $21^{\text {st }}, 2011$; accepted April $12^{\text {th }}, 2011$.

\begin{abstract}
In order to quantitatively predict the behavior of the material in the packed bed, a single particle model is developed to describe the combustion and sintering process inside an individual particle composed of multiple solid material fines, including iron ore, coke and limestone, and is applied to the combustion modeling of an iron ore sintering. By analyzing three typical fuel distribution cases using the developed single particle combustion model, the effects of temperature and oxygen concentration gradient inside the particle on heat and mass transfer and the combustion behavior of the iron ore sintering process are investigated. Considering the various combustion rates which are highly dependent on the fuel distribution methods, correction factor for single particle model is also introduced and systematically analyzed. The aim of this research is to supplement particle technology to conventional approach and it is found that the oxygen concentration gradient inside the particle is significantly affected from the mixing method thereby changing the completion times of sintering process.
\end{abstract}

Keywords: Iron Ore Sintering Bed, Porous Materials, Coating, Melting, Computer Simulation

\section{Introduction}

In the iron ore sintering process, a raw mix of fine particles of iron ore, limestone, and fuel coke fines form pseudo-particles after being mixed with water and these pseudo particles are then fed to the traveling grate to form a bed. After the feed material is introduced to the bed, combustion starts from the top of the bed by the ignition burner, and then the combustion front propagates downward into the bed while the entire bed is travelling. During the sintering process, the bed material experiences thermal drying, propagating combustion and various physicochemical and thermal phenomena.

In order to quantitatively predict the behavior of the material involved in the sintering process, mathematical models for the iron ore sintering bed have been developed. Previous studies [1-7] have attempted to describethe complicated phenomena of combustion and heat and mass transfer in the sintering bed, but there is still enough room for improvement. Numerical model based on sound physics could be effective in understanding the physicochemical mechanisms involved in the sintering process and ultimately in optimizing the sintering processes.

Muchi and Higuchi [1] used the Ranz equation for heat transfer in packed beds and principally took into account heat transfer, drying and coke combustion in their one dimensional modeling, and primarily focused on the coke combustion and predicted gas compositions with temperature distribution in the bed. Young [2] produced a mathematical model that allows the dynamic behavior of the bed to be studied when gas flow and properties of the mixture change as sintering proceeds. Cumming and Thurlby [3] and Patisson et al. [4] considered the change of the bed height and treated void fraction in detail that resulted from the surface melting of the iron ore by introducing shrinkage factor. In the model of Cumming and Thurlby [3], the surface and core of granules are at different temperatures. Nath et al. [5] developed a mathematical model which can be used to simulate both the static bed of the laboratory and the moving bed condition used in actual industrial plants. Mitterlehner [6] developed a model for the iron ore sintering process with a special focus on heat front propagation through the packed 
bed. In the model, coke particles and the other particles are treated separately to take into account the change of void volume as the diameter of a coke particle gradually shrinks with combustion. Yang et al. [7] developed a unified approach that can be applied to a variety of combustors. Base on the assumption that the bed materials are homogeneous and continuum, the governing mechanisms of the solid and the gas phases are modeled, and particularly, the solid materials are treated as multiple solid phases. Each component of solid materials that have different temperatures, physical properties and chemical compositions is applied with the consideration of radiative heat transfer. Komarov et al. [8] employed commercial CFD software package Phoenics which incorporates self-developed numerical code.

An essential simplification in previous investigations was the assumption of homogeneity inside a particle. Those studies only focused on the ideal case of surface reactions on a particle without considering the temperature and species profiles inside. A single solid particle is assumed to have one representative value, which means that there is no temperature and species concentration gradient inside the single particle. However, especially in the case of large particles, the processes are strongly controlled by heat and mass transfer inside the particle. Penetration of the reaction gas is influenced by intra-particle mass transfer. Tests [3] have proved that simple modeling assumption would be insufficient to simulate conditions near the top of the bed under the ignition hood with the low gas flow rates. Resistance to gaseous diffusion within the granules can greatly affect the reaction rates, particularly that of coke combustion. Granule surface temperatures, which affect convective heat transfer rates, may be considerably higher or lower than that of the mean granule temperature assumed [3]. Perters [9] proposed a numerical model for the packed bed moving on a forward acting grate by a discrete particle model considering the conversion process of a single particle. This approach considers the packed bed to be composed of a finite number of individual particles. Wurzenberger et al. [10] developed a combined transient single particle and a fuel-bed model for the thermal conversion of biomass in a packed bed furnace. A representative particle is chosen to be discretized in a radial direction at each grid point. Mass, momentum and energy balances are solved for the entire system. R. Johansson $e t$ al. [11] considered intra particle gradients to compare the impact of using a porous media approximation for modeling fixed bed combustion. By introducing two-dimensional particle model, intra particle gradients were taken into account. The particle model provides information on the internal heating of the solid particles and the internal rate of drying and devolatilizatioin. An important aspect of the three above works provided insight on the thermal processes in packed bed for single porous particles.

Figure 1(a) shows a simplified bed model from an actual fuel bed to an unsteady 1-D model. [12] The horizontal location of the fuel layer can be transformed from the elapsed time and the moving speed. Figure 1(b) conceptualizes the extension of the model from the previously developed iron ore sintering bed model to the present improved model. Yang et al. [7] proposed an unsteady 1D model of multiple solid phase materials for the numerical analysis of an iron ore sintering bed. In the model, the solid material is treated as multiple solid phases, which makes it possible to consider characteristics of different solid materials such as limestone, coke and iron ore. The objective of this paper is to develop an iron ore sintering bed model which takes the single particle into consideration and incorporates more information on individual particles in terms of the entire iron ore sintering bed.

\section{Modeling Approach}

\subsection{Intra-Particle Combustion Model}

Unlike previously proposed single particle model in which the particle was composed of a single solid phase, the single particle model proposed in this paper describes the combustion and sintering process inside an individual pseudo particle composed of multiple fines of solid material within the iron ore sintering bed (as shown in Figure 1). It is assumed that the size of the solid particle remains constant, while the particle density decreases as the conversion progresses.

The mathematical modeling of these phenomena involves constructing system equations and determining the sub-models required for each term of the governing equations. Governing equations have a form of unsteady 1-dimensional partial differential equations for spherical particles. For the gas phase, an oxygen transport equation is employed without the convection term for simplification. The source terms of each controlling equations are closely combined through the interaction between phases.

\subsection{Governing Equations for the Single Solid Particle}

\subsubsection{Gas Phase}

1) Oxygen diffusion

The oxygen diffusion equation is employed to take into account the influence of the oxide concentration gradient on char combustion. Conservation of oxygen depends on a chemical term and a diffusive flux.

$$
\frac{\partial\left(f C_{\mathrm{O}_{2}}\right)}{\partial t}=\frac{1}{r^{2}} \frac{\partial}{\partial r}\left[r^{2} f D_{e f f, \mathrm{O}_{2}} \frac{\partial C_{\mathrm{O}_{2}}}{\partial r}\right]+\dot{\omega}_{\mathrm{O}_{2}}
$$




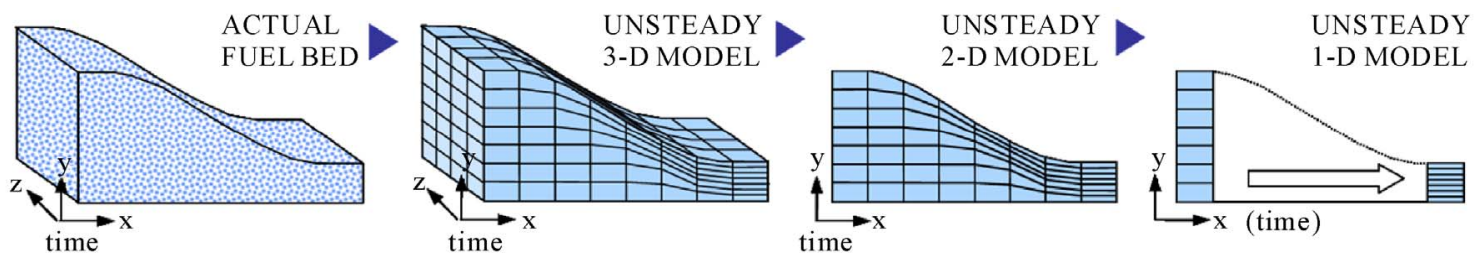

(a)
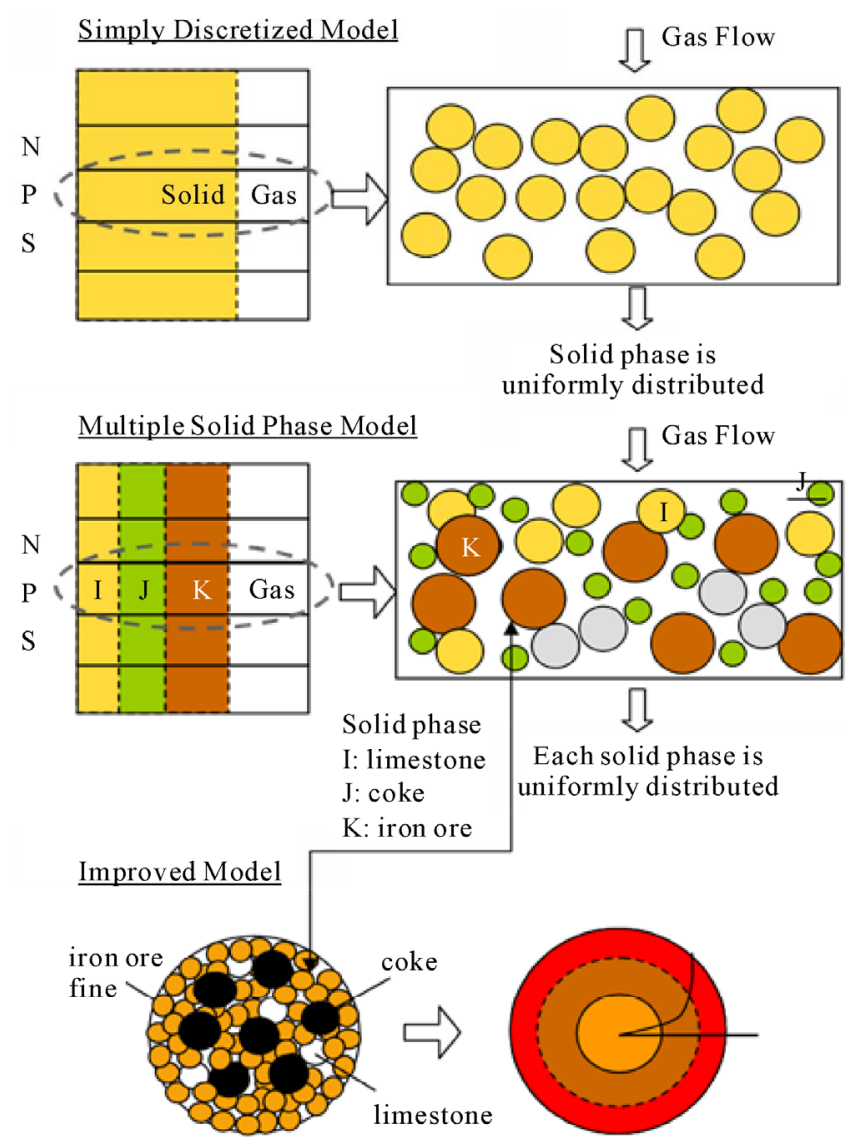

Actual Pseudo Particle

Temperature or Species Concentraction Gradient

(b)

Figure 1. Schematic of the of sintering bed model concept. (a) Simplification of bed model from actual fuel bed to unsteady 1-D model; (b) Extension from previously developed iron ore sintering bed model to the improved model.

where $f$ is particle porosity, $C$ is oxygen concentration, $D$ is the effective diffusion coefficient of oxygen considering the porosity and the influence of tortuosity on the diffusion, and $\dot{\omega}_{o_{2}}$ is the consumed mass by combustion with char.

\subsubsection{Solid Phase}

1) Mass

$$
\frac{\partial\left(\varepsilon \rho_{s}\right)}{\partial t}=\sum_{r_{s}} \dot{M}_{S, r_{s}}
$$

where $\varepsilon$ is the volume factor of solid in the particle, $\rho_{s}$ s the overall density of the particle, $\dot{M}_{S, r}$ is the mass loss of the solid phase through reactions, $r_{s}$ is the reaction number.

2) Energy

$$
\begin{aligned}
\frac{\partial\left(\varepsilon \rho_{s} C_{p, s} T_{s}\right)}{\partial t}= & \frac{1}{r^{2}} \frac{\partial}{\partial r}\left(\varepsilon r^{2} \lambda_{s} \frac{\partial T_{s}}{\partial t}\right)+\sum_{r_{s}} y \dot{M}_{S, r_{s}} \Delta H_{r_{s}} \\
& -\left(\sum_{r_{s}} \dot{M}_{S, r_{s}}\right) C_{P} T_{S}
\end{aligned}
$$


where Ts is the local particle temperature, $C_{p, s}$ is the over- all heat capacity of the particle, and $\lambda_{s}$ is the overall heat conductivity. Heat of the heterogeneous reactions is $\Delta H_{r_{s}}$. The second term on the right-hand side of this equation is the reaction heat absorbed by solids where $\mathrm{y}$ is the fraction of reaction heat absorbed by the solids. The third term is the sensible heat loss of evolved gas.

3) Component

$$
\frac{\partial\left(\varepsilon \rho_{s} m_{s, k}\right)}{\partial t}=\sum_{r_{s}} \dot{M}_{S, k, r_{s}}
$$

$\dot{m}_{s, k}$ is the component factor of the solid phase, and $\dot{M}_{S, k, r}$ is the mass loss of the components of the solid phase through reactions.

\subsection{Sub-Model}

\subsubsection{Drying}

Boiling is considered as the main process above the temperature of $373 \mathrm{~K}$. The process of drying is described based on energy balance

$$
\dot{\omega}_{\text {ch } 20}= \begin{cases}\frac{\left(T-T_{\text {evap }}\right) \rho c_{p}}{H_{\text {evap }} \Delta t} & T \geq T_{\text {evap }} \\ 0 & T<T_{\text {evap }}\end{cases}
$$

\subsubsection{Char Reactions}

The rates of carbon oxidation by stream and carbon dioxide are of the same order of magnitude, and are generally much slower than that with oxygen [13]. A differential approach of intrinsic modeling yields more accurate results than postulating a reacting or a shrinking core mode in advance [9].

The rate of char reaction with oxygen can be calculated as follows [7]:

$$
R_{C}=k_{r} C_{\mathrm{O}_{2}}=A_{r} T \exp \left(-\frac{E_{r}}{R T}\right) C_{\mathrm{O}_{2}}=2.3 T \mathrm{e}^{-11100 / T} C_{\mathrm{O}_{2}}
$$

After being transported across the outer annulus of the porous sintered part, the gas phase reactant diffuses to the surface of the unreacted char core or into the pores in the core. Oxygen reacts with the carbon of the char according to the following reaction scheme based on a combustion model by Hobbs et al. [14].

$$
\mathrm{C}+\frac{1}{2} \mathrm{O}_{2} \rightarrow \mathrm{CO}
$$

\subsubsection{Limestone Decomposition}

Limestone is one of the main components of sinter mix material. Its thermal decomposition is an endothermic process that occurs at the temperature of $600^{\circ} \mathrm{C}$.

The reaction equation can be expressed as

$$
\mathrm{CaCO}_{3} \rightarrow \mathrm{CO}_{2}+\mathrm{CaO}
$$

The reaction rate [6] is given as,

$$
R_{l}=1.75 \cdot 10^{6} \cdot \mathrm{e}^{-\frac{1.711 \cdot 10^{5}}{R T}}\left(m_{s, \mathrm{CaCO}_{3}}-m_{\mathrm{CaO}} \cdot \frac{M_{\mathrm{CaCO}_{3}}}{M_{\mathrm{CaO}}} \cdot \frac{p_{\mathrm{CO}_{2}}}{K_{e q}}\right)
$$

\subsubsection{Physical Properties}

Properties of the solid particle components such as fuel, iron ore and limestone are adopted from the literature [7]. As a result of the averaging process and the influence of tortuosity on the diffusion, an effective diffusion coefficient is used.

$$
\begin{aligned}
& D_{\text {eff }, \mathrm{O}_{2}}=D_{\mathrm{O}_{2}} f / \tau \\
& f, \tau \text { : porosity and tortuosity }
\end{aligned}
$$

Tortuosity is employed to consider the contribution of Knudsen diffusion, and porosity is the volume factor of the gas phase inside the particle.

The special heat of the mixture is given as,

$$
C p_{s}=\sum_{k}^{N_{s}} m_{s, k} C p_{s, k}
$$

The density of the mixture is given as,

$$
1 / \rho_{s}=\sum_{k} m_{s, k} / \rho_{s, k}
$$

The conductivity of the mixture is given as,

$$
1 / \lambda_{s}=\sum_{k} m_{s, k} / \lambda_{s, k}
$$

\subsubsection{Boundary Condition}

The boundary condition for the individual particle is,

$$
\left.\lambda_{s} \frac{\partial T_{s}}{\partial t}\right|_{r=R}=h\left(T_{O}-T_{R}\right)
$$

where $h$ is the convective heat transfer coefficient between the particle surface and the outer gas flow.

\subsection{Application of Intra-Particle Combustion Model-Fuel Distribution inside a Pseudo Particle}

To examine the adaptability of the developed model, typical single iron ore particles with various fuel distributions were chosen. Those are one of the various technologies which were developed to optimize the melting reaction by controlling quasi-particle structure as well as late coke addition [15]. From Method 1 to Method 4 (as shown in Figure 2), coke breezes are gradually transferred toward the particle surface and the diffusion distance of oxygen subsequently becomes shorter. By changing the mode of operation of the mixing drum, the fuel distribution pattern inside the pseudo-particles can 


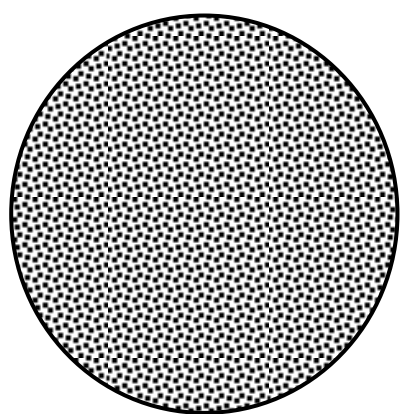

(a)

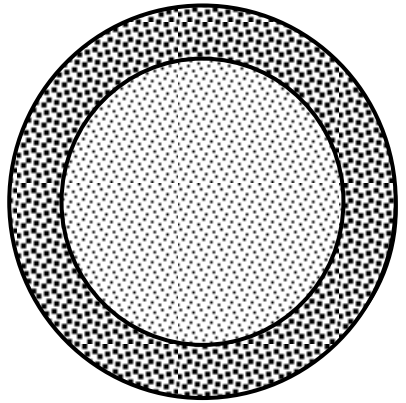

(b)

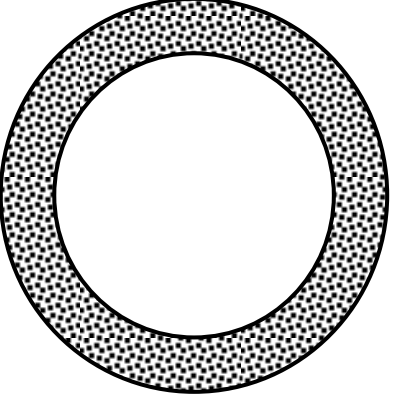

(c)

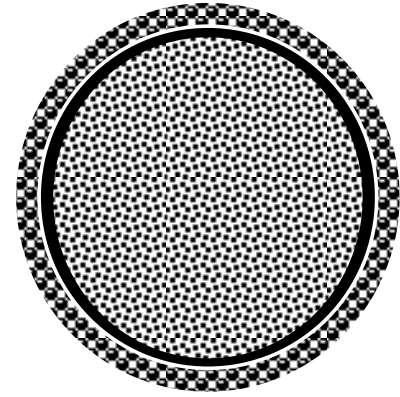

(d)

Figure 2. Schematic diagram of four different methods of adding fuel(total amount of fuel is constant), (a) Method 1: Homogeneous distribution; (b) Method 2: Layered fuel distribution 1.1\%, $0<r<0.8 R$; 7.15\%, $0.8 R<r<R$; (c) Method 3: Layered fuel distribution 2.0\%, $0<r<0.8 R ; 8.197 \%, 0.8 R<r<R$; (d) Method 4: Adding fuel entirely outside.

be controlled. The total amount of coke was kept constant to compare the sole effect of fuel adding methods.

For the simplicity, the assumption that all of the fuel grains are inserted into the outer layer of a solid particle was made as shown in Figure 3, contrary to the $\mathrm{O}_{2}$ concentration which was kept constant.

\section{Simulation Results and Discussion}

\subsection{Simulation Case and Results}

Table 1 presents the components of the bed material. For the single particle model, the physical properties of the solid phase can be determined by varying the composition of these components. For the entire bed model, these components can be divided into three solid phases [7].

Table 2 summarizes the initial calculation parameters used in this simulation. In an actual sintering plant, the diameter of pseudo particles ranges from $0.5 \mathrm{~mm}$ to 8 $\mathrm{mm}$ [4] and that of coke particles is $1 \mathrm{~mm}$ to $2 \mathrm{~mm}$. For convenience of simulation, the diameters of pseudo and coke particle are taken as $6 \mathrm{~mm}, 1 \mathrm{~mm}$ respectively. Initially, the temperature throughout the interior of the pseudo particle is $300 \mathrm{~K}$, while the particle is instanttaneously surrounded by an environment of $1373 \mathrm{~K}$.

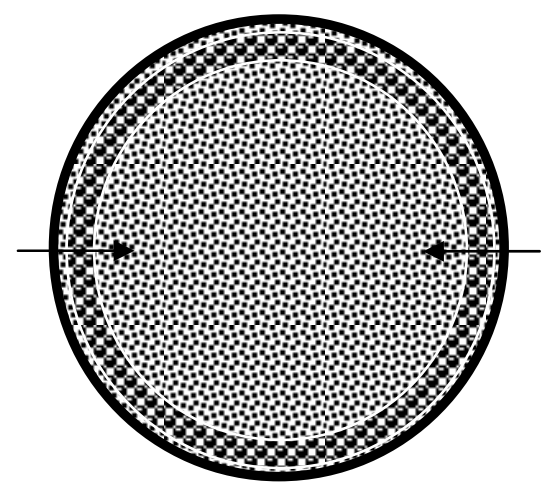

Figure 3. An approximate equivalent assumption for the modeling of Method 4.
Figure 4 shows the temperature and oxygen concentration distribution during the sintering process of a single solid particle. The developed single solid particle model properly describes the drying, limestone decomposition and coke combustion during the sintering process. The temperature gradient inside the particle is not obvious, but the oxygen concentration gradient inside the particle is significant. The reason is that the solid conductivity is sufficient to conduct heat quickly, while the effective diffusion coefficient of oxygen produces a resistance to oxygen diffusion inside the particle. In the sensitivity analysis, the effects of variations of solid conductivity and the oxygen effective diffusion coefficient for temperature and oxygen concentration are further discussed Figure 5 shows temperature profiles as a function of radius and time for the different fuel distribution methods inside a pseudo particle. In addition, a comparison of sintering times for each distribution methods is given in Table 3. The sintering time for a single particle is taken as the time that elapses before the particle reaches its maximum temperature.

In the case of fuel distribution only at the outer surface (Method 4), sintering process is clearly promoted where it shows higher temperature and faster combustion speed. This result can be attributed to the relatively higher oxygen diffusivity generated from the adding fuel outside only method. In other words, oxygen diffusion is restrained when the fuel is placed inside pseudo particles. The effect of bonding and melting disturb the reaction between oxygen and fuel, thereby reduces the fuel combustion rate.

Figure 6 shows a comparison of oxygen concentration distributions for two modes of fuel distribution. The oxygen concentration inside the particle of Method 1 is much lower than that of Method 3 which is similar to Method 4. Also, it can be found that in the Method 3, the oxygen concentration gradient exists only in the outer layer where all the fuel is placed. Lower oxygen concen- 
Table 1. Initial composition of the bed material.

\begin{tabular}{ccccccc}
\hline Components & Moisture & Coke & $\mathrm{Fe}_{2} \mathrm{O}_{3}$ & $\mathrm{CaCO}_{3}$ & $\mathrm{CaO}$ & Inertmaterial \\
\hline Concentrtion(mass\%) & 7 & 4 & 52.29 & 9.75 & 1 & 25.96 \\
\hline
\end{tabular}

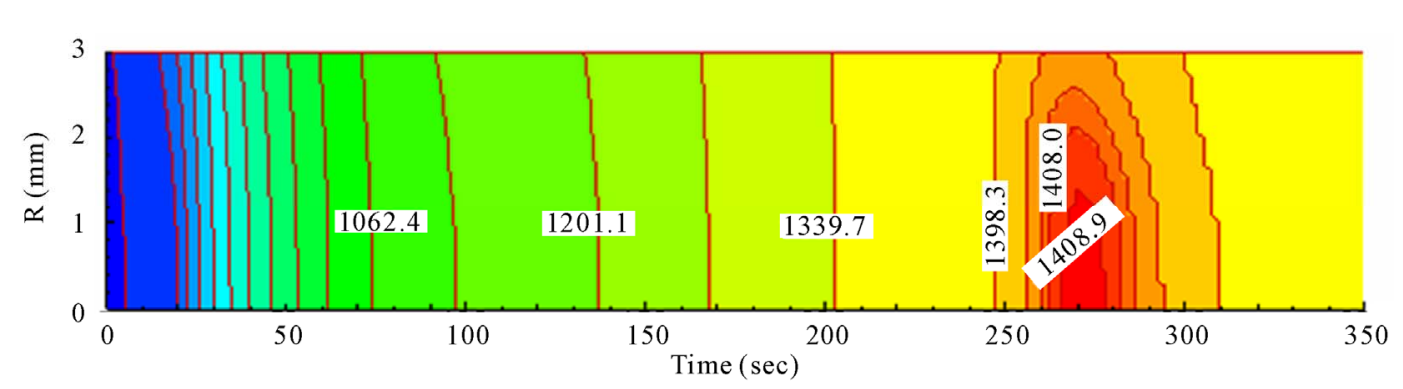

(a)

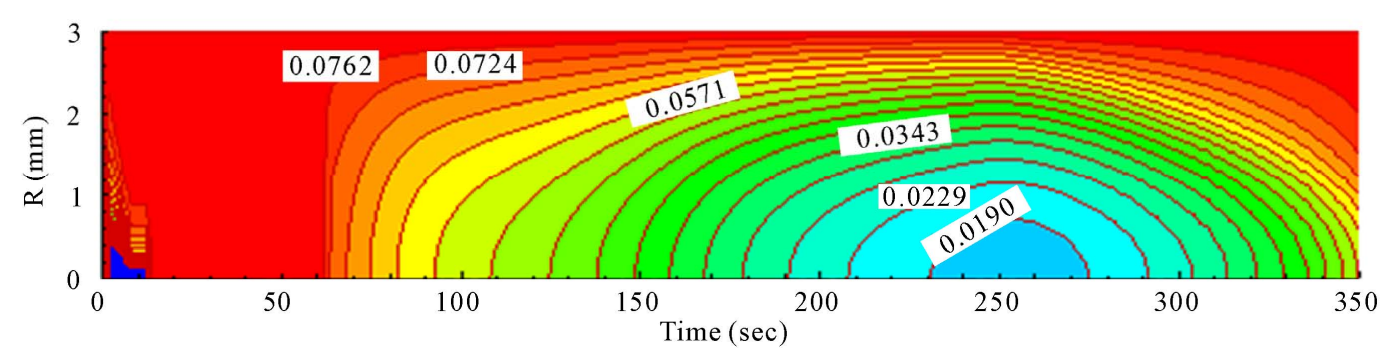

(b)

Figure 4. Particle temperature andoxygen concentration as a function of radius and time for sintering process of a single solid

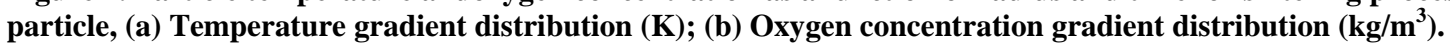

Table 2. Other simulation parameters.

\begin{tabular}{cc}
\hline Pseudo-particle diameter $(\mathrm{mm})$ & 6 \\
Coke breeze diameter $(\mathrm{mm})$ & 1 \\
Velocity of outer flow $(\mathrm{m} / \mathrm{s})$ & 0.4 \\
Heating up temperature $(\mathrm{K})$ & 1373 \\
Oxygen concentration in heating gas(mass $\%)$ & 23.3 \\
\hline
\end{tabular}

Table 3. Comparison of sintering time of various fuel adding methods.

\begin{tabular}{ccccc}
\hline $\begin{array}{c}\text { Fuel addition } \\
\text { method }\end{array}$ & Method 1 & Method 2 & Method 3 & Method 4 \\
\hline $\begin{array}{c}\text { Sintering Time } \\
\text { (s) }\end{array}$ & 275 & 255 & 251 & 235 \\
\hline
\end{tabular}

tration levels would enhance reductive reactions (Equation (15)). When the fuel is located only at the outer surface, the $\mathrm{FeO}$ content can also be reduced according to the following relation.

$$
\begin{aligned}
& 3 \mathrm{Fe}_{2} \mathrm{O}_{3}+\mathrm{CO}=2 \mathrm{Fe}_{3} \mathrm{O}_{4}+\mathrm{CO}_{2} \\
& \mathrm{Fe}_{3} \mathrm{O}_{4}+\mathrm{CO}=3 \mathrm{FeO}+\mathrm{CO}_{2}
\end{aligned}
$$

From the Figures $\mathbf{5}$ and $\mathbf{6}$, the temperature gradient in- side the single solid particle is appeared to be negligible. However, those results show that significant oxygen concentration gradient exists along the radius of pseudo particle.

\subsection{Sensitivity Analysis}

In this numerical model, some calculation parameters were arbitrarily selected since those were not able to be decided by experimental approach. Therefore, their value should be checked carefully, because variations in their values can affect simulation results significantly. For this reason, a sensitivity analysis was performed for two major parameters. Those include the thermal conductivity of the solid particle and the effective diffusion coefficient of oxygen through the particle medium.

Solid conductivity is related to the heat transfer inside the pseudo-particle. Temperature distributions for various values of solid conductivity $\lambda_{s}$ are considered and it is found that this parameter has a meaningful effect on the temperature distribution when its value is very low, compare to the normal range of solid conductivity. Adding to that, the effective diffusion coefficient is examined and it is basically related to the oxygen concentration distribution inside the pseudo particle. Therefore, this study has analyzed the various values of the effective 


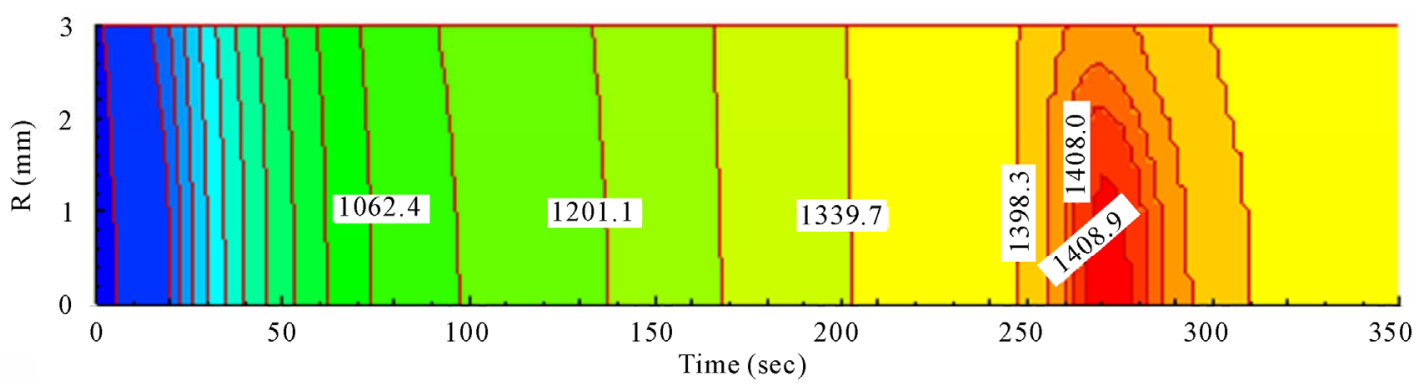

(a)

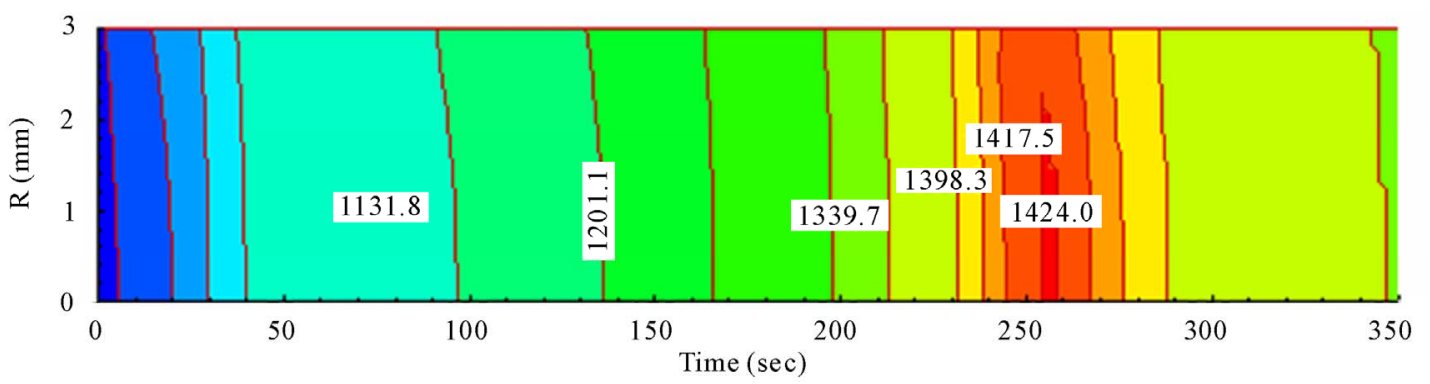

(b)

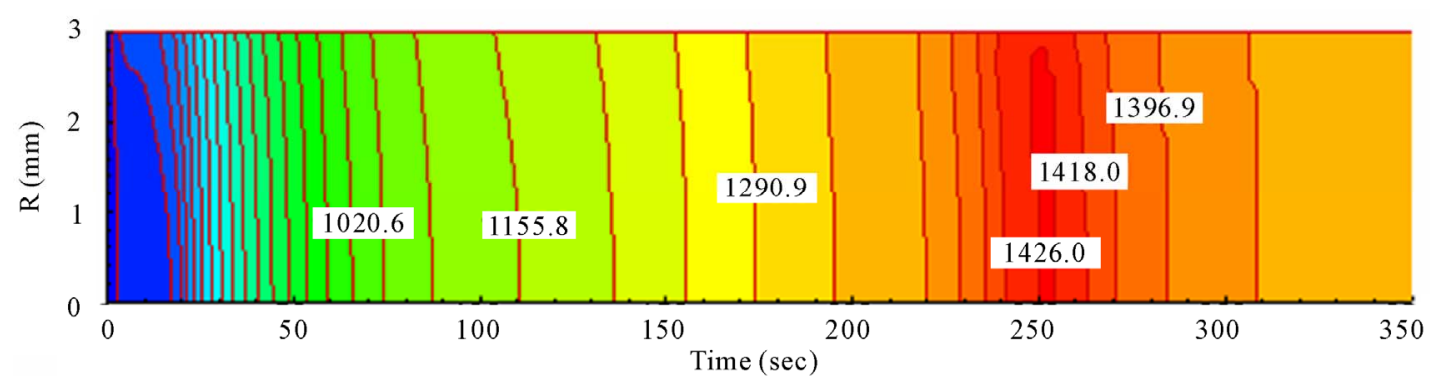

(c)

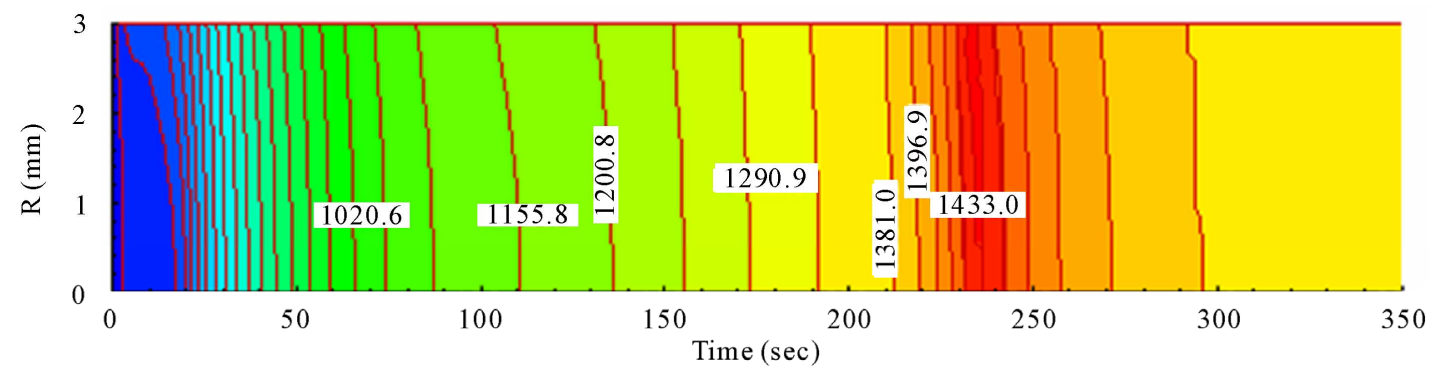

(d)

Figure 5. Particle temperature as a function of radius and time for the sintering process for different fuel adding methods (K). (a) Method 1: Homogeneous distribution; (b) Method 2: Layered fuel distribution1: 1\%, $0<r<0.8 R$; $7.15 \%, 0.8 R<r<R$; (c) Method 3: Layered fuel distribution 2: $0 \%, 0<r<0.8 R$; 8.197\%, $0.8 R<r<R$; (d) Method 4: Adding all fuel outside.

diffusion coefficient $D_{\text {eff, } \mathrm{O}_{2}}$. The diffusion parameter plays a significant role on the oxygen concentration distribution, as well as on the sintering time, which implies that this parameter should be carefully determined in the model studies.

\section{Extension of the Intra-Particle Model to the Bed Combustion}

\subsection{Extension of Intra-Particle Combustion Model}

In the case of the normal mode of fuel distribution, in 


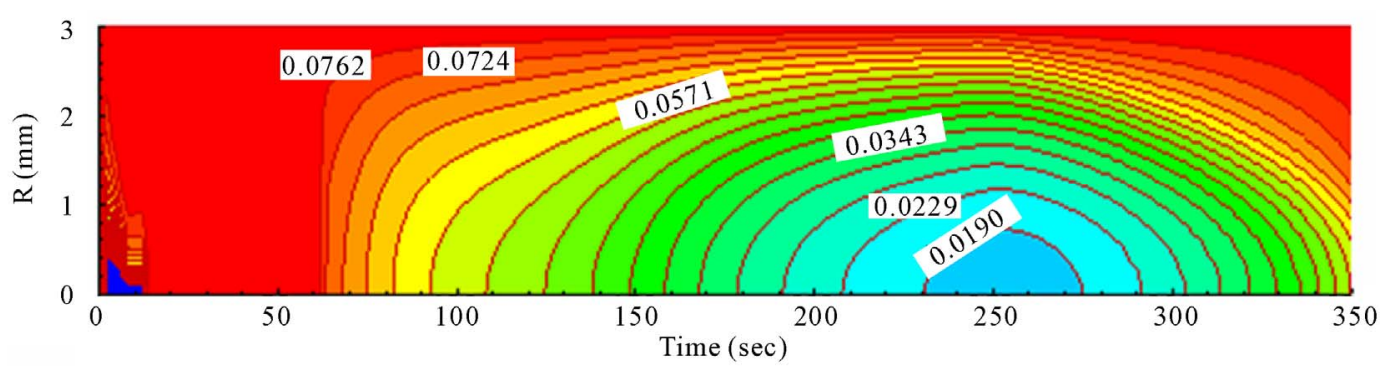

(a)

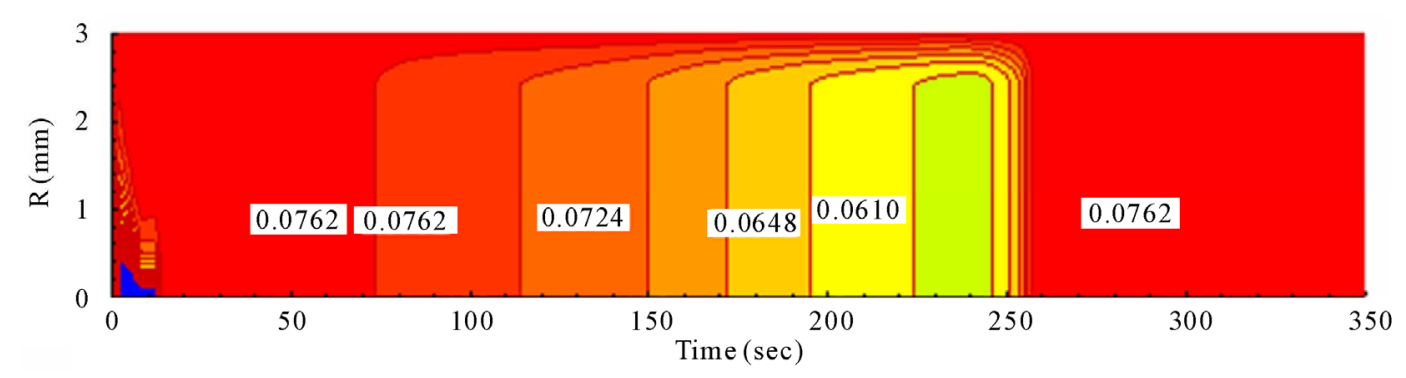

(b)

Figure 6. Comparison of oxygen concentration distributions $\left(\mathrm{kg} / \mathrm{m}^{3}\right)$. (a) Method 1; (b) Method 3.

which the fuel is evenly distributed inside a particle, the speed of the sintering process is determined by the coke combustion speed [14] which is in turn influenced by factors including oxygen concentration, char combustibility, char particle size, char mass fraction and gas velocity. The reaction rate of char combustion is deter-mined from the kinetic rate, diffusion rate and internal mass transport in the ash layer of the particle. It can be expressed as in Equation (16) [14]

$$
\begin{gathered}
R_{C}=\frac{A_{s} v_{s} W_{c h a r} C_{g}}{\frac{1}{k_{r}}+\frac{1}{k_{m}}+\frac{1}{k_{e f f}}} \\
\text { where } A_{s}=\left(\pi d_{p}^{2}\right) \frac{6 f_{V, I}}{\pi d_{p}^{3}}, k_{r}=A_{r} T \exp \left(-\frac{E_{r}}{R T}\right) \\
k_{m}=\frac{S h D}{d_{p}}, \frac{1}{k_{e f f}}=\frac{(1-F)) d_{p}}{2 D_{e f f}}
\end{gathered}
$$

The single particle model discussed above clearly shows that the fuel combustion conditions where the various fuel distributions were applied differ from each other. Figure 7 shows the oxygen concentration profile in the neighborhood of a coke particle and it indicates that the oxygen diffusion process inside a pseudo particle is slightly different from that of a separate coke particle.

Considering the various combustion rates which are highly dependent on the fuel distribution methods, it can be an appropriate measure introducing the correction factor. Since the speed of the sintering process may re- flect the fuel combustion speed, the correction factor for the coke combustion rate can be determined according to the sintering time. Here, based on the coke combustion rate value of Method 1, thecoke combustion rate of Method 4 can be expressed as

$$
R_{C}=\frac{A_{s} v_{s} W_{c h a r} C_{g}}{\frac{1}{k_{r}}+\frac{1}{k_{m l}}+\frac{1}{k_{e f f}}}, \quad \text { where } k_{m l}=\xi k_{m}
$$

In the equation shown above, $k_{m l}$ and $\xi$ are the diffusion rate in the iron ore particle layer, and the correction factor respectively. From the sintering times of the Method 1 and Method 4 which are brought from completion of sintering process, the correction factor for Method 4 can be traced as 1.4 in comparison with the Method 1. It should be also noted that increased or decreased combustion temperature due to the different coating method influences diffusion rate [17], and suggested correction factor would be slightly different if the change of permeability is considered. Several studies have been done on the permeability of mixtures of raw materials and it is found that the method of the separate coke addition leads to more permeable condition [18]. However, oxygen diffusion is primarily discussed in this research and newly adopted factor seems to reflect the time interval between Method 1 and Method 4. Under the condition where the enhanced permeability is applied, comparatively lowered correction factor is expected and this consequence can be attributed to the increased air flow rate. 


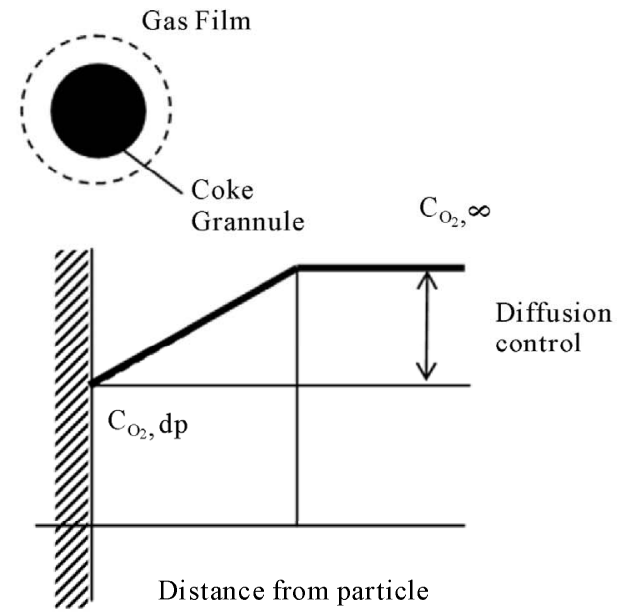

Coke Grannule surface

(a)

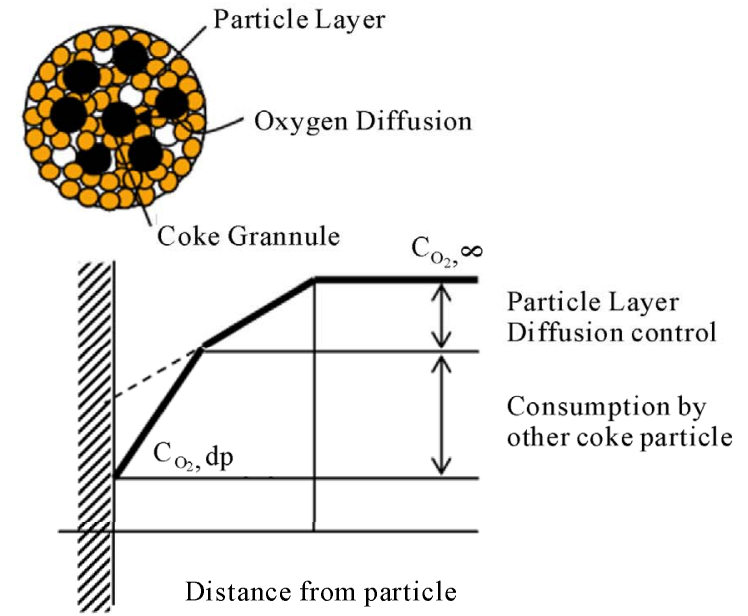

Coke Grannule surface

(b)

Figure 7. Oxygen concentration profile in coke particle neighborhood. (a) Separate coke particle [15]; (b) Coke Particle inside a pseudo particle.

\subsection{Results and Discussion}

In the Figure 8, the simulation results of temperature distribution are presented, and the fuel distribution cases

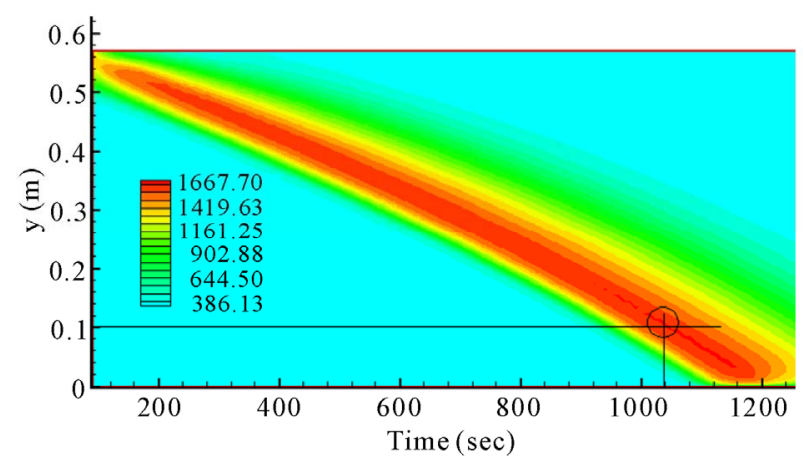

(a)

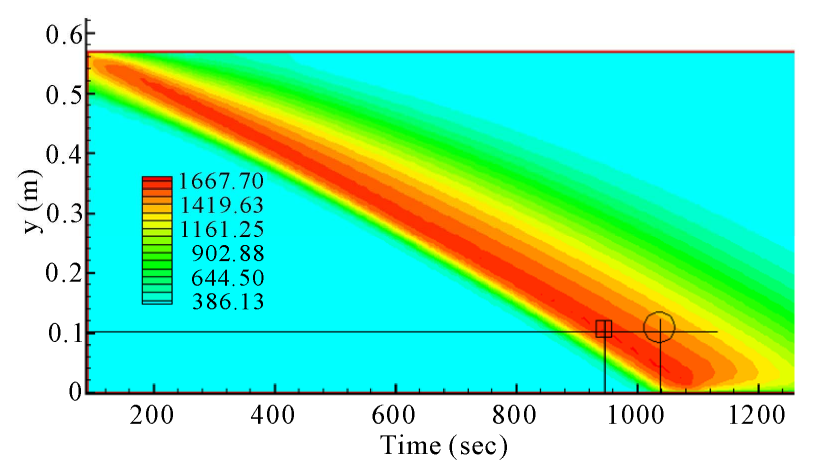

(b)

Figure 8. Temperature distribution for Method 1 (a) and 4(b) (570 mm H). (a) Method 1; (b) Method 1. for Method 1 and 4 are generally discussed. To compare the combustion speed, $\mathrm{y}=100 \mathrm{~mm}$ is chosen to be a base level, and the time when each flame front reaches the point are calculated which are obtained as $1040 \mathrm{~s}, 950 \mathrm{~s}$ respectively. From the consequence, it is attained that the front of the combustion zone of Method 4 penetrates the bottom quicker than that of Method 1. In other word, the propagation of combustion of Method 4 is faster and the difference between the total sintering times of the two methods is: $(1040-950) / 1040=8.6 \%$.

An immediate cause for the above results can be explained by the different oxygen diffusion processes, and it should be noted that the surrounding environment of coke surface is one of the most influential factors in different fuel adding methods. The oxygen diffusivity of Method 4, late coke addition, is supposed to be higher than that of Method 1. Having the difference in the nature of diffusivity between Method 1 and 4 consequently results in the reduction of sintering time for the late coke addition. For the variation of diffusivity, newly adopted correction factor was employed and it reflects different modes of fuel distribution. In conclusion, the approach described in this research is one example of the cases where the improved model could be used to simulate the sintering process with different modes of fuel distribution.

\section{Conclusions}

Adding to the previously developed combustion bed model, a refined mathematical model for the iron ore sintering process is proposed. The aim of this research is 
to supplement particle technology to conventional approach where the assumption of homogeneity inside a particle is applied. The presented single particle model isincorporated into the previously constructed entire combustion bed model and it successfully describes the drying, limestone decomposition and coke combustion in the sintering process.

It is found that the temperature gradient inside the particle is not obvious, but the oxygen concentration gradient inside the particle is significant. A sensitivity analysis was performed and it revealed that the oxygen concentration gradient inside the particle is significant, while the temperature gradient inside the particle can be neglected. The simulation results for the different mode of fuel distribution are also presented and the prediction for the completion times of sintering process is discussed.

\section{REFERENCES}

[1] I. Muchi and J. Higuchi, "Theoretical Analysis of the Operation of Sintering," Iron and Steel, Vol. 56, No. 3, March 1970, pp. 371-381.

[2] R. W. Young, "Dynamic Mathematical Model of (Iron-Ore) Sintering Process," Ironmaking and Steelmaking, Vol. 4, No. 6, 1977, pp. 321-328.

[3] M. J. Cumming and J. A. Thurlby, "Developments in Modeling and Simulation of Iron Ore Sintering," Ironmakingand Steelmaking, Vol. 17, No. 4, 1990, pp. 245- 254.

[4] F. Patisson, J. P. Bellot, D. Ablitzer, E. Marli, C. Dulcy and J. M. Steiler, "Mathematical Modeling of Iron Ore Sintering Process," Ironmaking and Steelmaking, Vol. 18, No. 2, 1991, pp. 89-95.

[5] N. K. Nath, A. J. Silva and N. Chakraborti, "Dynamic Process Modeling of Iron Ore Sintering," Steel Research, Vol. 68, No. 7, 1997, pp. 285-292.

[6] J. Mitterlehner, G. Loeffler and F. Winter, "Modeling and Simulation of Heat front Propagation in the Iron Ore Sintering Process," ISIJ International, Vol. 44, No. 1, 2004, pp. 11-20. doi:10.2355/isijinternational.44.11

[7] W. Yang, C. Ryu, S. Choi, E. Choi, D. Lee and W. Huh, "Modeling of Combustion and Heat Transfer in an Iron Ore Sintering Bed with Considerations of Multiple Solid Phases," ISIJ International, Vol. 44, No. 3, 2004, pp. 492-499. doi:10.2355/isijinternational.44.492

[8] S. Komarov, H. Shibata, N. Hayashi and E. Kasai, "Numerical and Experimental Investigation on Heat Propaga- tion through Composite Sinter Bed with Non-Uniform Voidage: Part 1 Mathematical Model and Its Experimental Verification," Interantional Journal of Iron and Steel Research, Vol. 17, No. 10, 2010, pp. 1-7.

[9] A. Dziugys and B. Peters, "An Approach to Simulate the Motion of Spherical and Non-Spherical Fuel Particles in Combustion Chambers," Granular Matter, Vol. 3, No. 4, 2001, pp. 231-266. doi:10.1007/PL00010918

[10] J. C. Wurzenberger, S. Wallner and H. Raupenstrauch, "Thermal Conversion of Biomass: Comprehensive Reactor and Particle Modeling," AIChE Journal, Vol. 48, No. 10 , October 2002, pp. 2398-2411. doi:10.1002/aic.690481029

[11] R. Johansson, H. Thunman and B. Leckner, "Influence of Intraparticle Gradients in Modeling of Fixed Bed Combustion," Combustion and Flame, Vol. 149, No. 1, April 2007, pp. 49-62. doi:10.1016/j.combustflame.2006.12.009

[12] W. Yang, C. Ryu, S. Choi, E. Choi, D. Ri and W. Huh, "Mathematical Model of Thermal Process in an Iron Ore Sintering Bed," Metals and Materials International, Vol. 10, No. 5, 2004, pp. 493-500. doi:10.1007/BF03027355

[13] F. D. Skinner and L. D. Smoot, "Pulverized-Coal Combustion and Gasification," Noyes Publications, Park Ridge, 1984.

[14] M. L. Hobbs, P. T. Radulovic and L. D. Smoot, "Combustion and Gasification of Coals in Fixed-Beds," Progress in Energy and Combustion Science, Vol. 19, No. 6, 1993, pp. 505-586. doi:10.1016/0360-1285(93)90003-W

[15] N. Oyama, T. Higuchi, S. Machida, H. Sato and K. Takeda, "Effect of High-Phosphorous Iron Ore Distribution in Quasi-Particle on Melt Fluidity and Sinter Bed Permeability during Sintering," ISIJ Intermational, Vol. 49, No. 5, 2009, pp. 650-658.

doi:10.2355/isijinternational.49.650

[16] T. Jerzy, "Coal Combust," Krieger Publishing, Malabar, 1994.

[17] J. Song, C. Jeon and A. Boehman, "Impact of Oxygen Diffusion on the Combustion Rate of in-Bed Soot Particles," Energy and Fuels, Vol. 24, No. 4, 2010, pp. 24182428. doi:10.1021/ef900692m

[18] E. Kasai, W. J. Rankin and J. F. Gannon, "The Effect of Raw Mixture Properties on Bed Permeability during Sintering," ISIJ International, Vol. 29, No. 1, 1989, pp. 3342. doi:10.2355/isijinternational.29.33 


\section{Nomenclature}

$C$ molar concentration, $\mathrm{kmol} / \mathrm{m}^{3}$

$E$ activation energy, $\mathrm{J} / \mathrm{kmol}$

$f_{i p} \quad$ ratio of internal pore generation

$H$ heat of reaction or combustion, $\mathrm{J} / \mathrm{kmol}$

$h$ enthalpy, J; convection coefficient, $\mathrm{W} / \mathrm{m}^{2} \mathrm{~K}$

$k$ rate constant, $\mathrm{s}^{-1}$; conductivity, $\mathrm{W} / \mathrm{mK}$; mass transfer coefficient, $\mathrm{m} / \mathrm{s}$

$M \quad$ volumetric mass generation rate, $\mathrm{kg} / \mathrm{m}^{3} \mathrm{~s}$

$m$ mass fraction

$q$ volumetric heat generation rate, $\mathrm{J} / \mathrm{m}^{3} \mathrm{~s}$

$R$ universal gas constant

$R$ reaction rate, $\mathrm{kmol} / \mathrm{m}^{3} \mathrm{~s}$

$T$ temperature, $\mathrm{K}$

$t$ time, $\mathrm{s}$

$V$ volume, $\mathrm{m}^{3}$

$v$ superficial velocity, $\mathrm{m} / \mathrm{s}$
$W \quad$ molecular weight, $\mathrm{kg} / \mathrm{kmol}$

$y \quad$ vertical coordinate, $\mathrm{m}$

Greeks

$\varepsilon$ porosity

$\kappa \quad$ absorption coefficient, $\mathrm{m}^{-1}$

$v$ stoichiometric coefficient

$\rho$ density, $\mathrm{kg} / \mathrm{m}^{3}$

$\phi \quad$ general scalar quantity

\section{Subscripts}

eff diffusion through the ash layer

$g$ gas phase

ip internal pore

$j \quad$ chemical species of the solid phase

$k \quad$ reaction or combustion process

$m$ mass transfer

$o$ initial value

$r \quad$ kinetic 